\title{
Disorders of the erythrocyte membrane
}

\author{
Sophia Delicou, Aikaterini Xydaki, Chryssanthi Kontaxi, Konstantinos Maragkos
}

Thalassemia and Transfusion Unit, Hippokrateio Hospital, Athens, Greece

\begin{abstract}
Hemolytic anemia due to abnormalities of the erythrocyte membrane comprises an important group of inherited disorders. These include hereditary spherocytosis, hereditary elliptocytosis, hereditary pyropoikilocytosis, and the hereditary stomatocytosis syndromes. The erythrocyte membrane skeleton composed of spectrin, actin, and several other proteins is essential for the maintenance of the erythrocyte shape, reversible deformability, and membrane structural integrity in addition to controlling the lateral mobility of integral membrane proteins. These disorders are characterized by clinical and laboratory heterogeneity and, as evidenced by recent molecular studies, by genetic heterogeneity. Defects in various proteins involved in linking the lipid bilayer to membrane skeleton result in loss in membrane cohesion leading to surface area loss and hereditary spherocytosis while defects in proteins involved in lateral interactions of the spectrin-based skeleton lead to decreased mechanical stability, membrane fragmentation and hereditary elliptocytosis. The disease severity is primarily dependent on the extent of membrane surface area loss. Treatment with splenectomy is curative in most patients.
\end{abstract}

\section{Introduction}

Antonie van Leeuwenhoek, ${ }^{1}$ a brilliant Dutch microscopist, who observed and described the red cell, was the first to publish, in Philosophical Transactions of the Royal Society in 1675, a remarkable description of the unique features of human red blood cells (RBC). The non-nucleated erythrocyte is unique among human cells in which the plasma membrane, it is only a structural component, and accounts for all its diverse antigenic, transport, and mechanical characteristics.

The erythrocyte membrane ${ }^{2}$ is the most thoroughly studied biologic membrane. Although it constitutes only about $1 \%$ of the total weight of the red cell, the membrane plays a pivotal role in the maintenance of erythrocyte integrity in different ways. It responds to erythropoietin during erythropoiesis and imports the

Correspondence: Sophia Delicou, 114 Vasillisis Sofias Str. Athens, 115 27, Greece.

E-mail: sophiadelicou@gmail.com

Key words: Hemolytic anemia; hereditary spherocytosis; hereditary elliptocytosis; hereditary pyropoikilocytosis; hereditary stomatocytosis.

Received for publication: 3 January 2014.

Accepted for publication: 1 February 2014

This work is licensed under a Creative Commons Attribution NonCommercial 3.0 License (CC BY-NC 3.0).

(C) Copyright S. Delicou et al., 2015

Licensee PAGEPress, Italy

Italian Journal of Medicine 2015; 9:323-329

doi:10.4081/itjm.2015.470 iron required by the cell for hemoglobin $(\mathrm{Hb})$ synthesis. It retains vital compounds as organic phosphates and removes metabolic waste. The erythrocyte membrane sequesters the reductants required to prevent corrosion by oxygen. It helps to regulate erythrocyte metabolism by selectively and reversibly binding and inactivating glycolytic enzymes. It exchanges chloride and bicarbonate ions and maintains an adequate $\mathrm{pH}$. The membrane maintains a slippery exterior so that erythrocytes do not adhere to endothelial cells or aggregate and occlude the microcirculation, furthermore it provides strength and flexibility while enduring to circulatory stresses during its 120 days life span. The erythrocyte membrane is composed of mobile, asymmetrically distributed proteins and lipids that interact in a variety of ways. In this review are discussed the two of the most common abnormalities of red cell shape, hereditary spherocytosis, elliptocytosis, and miscellaneous disorders that affect the erythrocyte membrane.

\section{Hereditary spherocytosis}

Hereditary spherocytosis (HS) is the most common congenital hemolytic anemia in Caucasians, with an estimated prevalence ranging from 1:2000 to $1: 5000 .{ }^{3}$ Approximately $75 \%$ of cases display an autosomal dominant pattern of inheritance, the remaining comprise recessive forms and de novo mutations. ${ }^{4}$ It was first recognized more than 100 years ago by two Belgian physicians, Vanlair and Masius who gave the description of a woman who suffered from anemia, jaundice, splenomegaly and recurrent abdominal pain. Later a case report of Minkowski in 1900 and the classic description of osmotic fragility and reticulocytosis by Chauffard stated the diagnosis. 
Four abnormalities in red cell membrane proteins ${ }^{5}$ have been identified and include: i) spectrin deficiency alone; ii) combined spectrin and ankyrin deficiency; iii) band 3 deficiency; and iv) protein 4.2 defects. Spectrin deficiency is the most common defect.

\section{Spectrin deficiency}

Mutations of $\alpha$-spectrin ${ }^{6}$ are associated with recessive forms of HS, whereas mutations of $\beta$-spectrin occur in families with autosomal dominant forms of HS. ${ }^{7}$ The synthesis of $\alpha$-spectrin is 3 -fold greater than that of $\beta$-spectrin. The excess $\alpha$ chains are normally degraded. Heterozygotes for $\alpha$-spectrin defects produce sufficient normal $\alpha$-spectrin to balance normal $\beta$-spectrin production. Defects of $\beta$-spectrin are more likely to be expressed in the heterozygous state because synthesis of $\beta$-spectrin is the rate-limiting factor. Red cell membranes isolated from individuals with autosomal recessive HS have only $40-50 \%$ of the normal amount of spectrin (relative to band protein 3), whereas red cell spectrin levels range from $60-80 \%$ of the normal amount in the autosomal dominant form of HS.

Identification of an $\alpha$-spectrin mutation ${ }^{8}$ involves a point mutation at codon (969), resulting in an amino acid substitution (alanine/aspartic acid) at the corresponding site of $\alpha$-spectrin in $50 \%$ of patients with severe recessive HS. Mutations involving the $\alpha$-spectrin $\beta$-spectrin gene also occur, each resulting in spectrin deficiency. The first identified point mutation leads to a defective binding of spectrin to protein 4.1. Several other $\beta$-spectrin mutations have been identified. Some of these mutations result in impaired $\beta$-spectrin synthesis. Others produce unstable $\beta$-spectrins or abnormal $\beta$-spectrins that do not bind to ankyrin and undergo proteolytic degradation.

\section{Ankyrin defects}

$\mathrm{HS}^{9-11}$ is described in patients with translocation of chromosome 8 or deletion of the short arm of chromosome 8 where the ankyrin gene is located, and patients with HS and deletion of chromosome 8 are shown to have a decrease in red cell ankyrin content. Ankyrin is the principal binding site for spectrin on the red cell membrane. Studies of cytoskeletal protein assembly in reticulocytes indicate that ankyrin deficiency leads to decreased incorporation of spectrin. In HS caused by ankyrin deficiency, a proportional decrease in spectrin content occurs, although spectrin synthesis is normal. Of particular interest, $75-80 \%$ of patients with autosomal dominant HS have combined spectrin and ankyrin deficiency and the 2 proteins are diminished equally.

\section{Band 3 deficiency}

Band 3 deficiency ${ }^{12,13}$ has been recognized in 10 $20 \%$ of patients with mild-to-moderate autosomal dominant HS. These patients also have a proportionate decrease in protein 4.2 content on the membrane. In some people with HS who are deficient in band 3, the deficiency is considerably greater in older RBCs. This suggests that band 3 protein is unstable.

\section{Protein 4.2 (pallidin) deficiency}

Hereditary hemolytic anemia has been described in patients with a complete deficiency of protein 4.2. ${ }^{14,15}$ Spherocytes, elliptocytes, or sphero-ovalocytes have characterized RBC morphology. Deficiency of protein 4.2 in HS is relatively common in Japan. One that appears to be common in the Japanese population (protein 4.2 Nippon) is associated in the homozygous state with a red cell morphology described as spherocytic, ovalocytic, and elliptocytic. Another mutant protein 4.2 (protein 4.2 Lisboa) is caused by a deletion that results in a complete absence of protein 4.2. This is associated with a typical HS phenotype.

\section{Pathophysiology and mechanisms of membrane surface loss}

There are two hypotheses concerning the mechanism of membrane loss. ${ }^{7,16,17}$ In hypothesis 1 it is assumed that the membrane (the lipid bilayer and integral membrane proteins) is directly stabilized by interactions with spectrin or other elements of the membrane skeleton. Spectrin-deficient areas, lacking support, bud off, leading spherocytocis. In hypothesis 2 it is assumed that the membrane is stabilized by interactions of band 3 with neighboring lipids. The influence of band 3 extends into the lipid milieu because the first layer of immobilized lipids are missing. Spectrin/ankyrin deficiency allows band 3, owing to a targeted gene disruption, has marked membrane vesiculation and spherocytosis despite a nearly intact membrane skeleton.

\section{Clinical presentation}

The clinical presentation ${ }^{18,19}$ of hereditary spherocytosis is primarily dependent on the severity of hemolysis. Prolonged or excessive hyperbilirubinemia in the neonatal period may be an early manifestation of severe disease. In older children and young adults, symptoms of anemia, intermittent jaundice, or splenomegaly may lead to evaluation and diagnosis. Hereditary spherocytosis resulting from autoso- 
mal dominant inheritance is commonly associated with a family history of anemia, jaundice, splenectomy, cholelithiasis, and cholecystectomy. A negative family history is to be expected in patients in whom HS results from spontaneous mutation or autosomal recessive inheritance. In those kindred with autosomal recessive inheritance, the presumed homozygotes have marked spherocytosis and severe hemolysis. Patients with interstitial gene deletions in chromosome 8p11.1-8p21 $1^{7,20,21}$ that include ankyrin and neighboring genes have psychomotor retardation and hypogonadism. The observation that erythrocyte ankyrin and erythrocyte $\beta$-spectrin are expressed in muscle, brain, and spinal cord, raises the hypothesis that patients with HS also suffer from defects of these proteins.

\section{Laboratory features}

\section{Peripheral blood smear}

Spherocytes are the hallmark of HS. They are dense, round, and hyperchromic, lack pallor and have a decreased mean diameter. In most HS patients spherocytes and microspherocytes are the only abnormal cells on the peripheral smear. ${ }^{22,23}$ Acanthosytes or hyperchromic echinocytes are present in patients with $\beta$-spectrin defects. Acanthopoikilocytes and ovalostomatocytes have been observed in some patients with protein 4.1 deficiency.

\section{Red cell indices}

Most patients have mild to moderate anemia ( $\mathrm{Hb}$ : 9-12 g/dL), or no anemia at all. In the most severe cases the hemoglobin may drop to levels as low as 4$5 \mathrm{~g} / \mathrm{dL}$. The mean corpuscular hematocrit concentration of HS red cells is increased owing to relative cellular dehydration.

\section{Osmotic fragility test}

Osmotic fragility testing ${ }^{24}$ is performing by suspending red cells in increasingly hypotonic buffered $\mathrm{NaCl}$. In hypotonic solutions normal erythrocytes are able to increase their volume by swelling until they become spherical and burst, releasing hemoglobin into the supernatant. Cells that begin with a decreased surface/volume ratio, like spherocytes or stomatocytes, reach the spherical limit at a higher $\mathrm{NaCl}$ concentration than normal cells and termed osmotically fragile. After incubation at $37^{\circ} \mathrm{C}$ for $24 \mathrm{~h}$, HS red cells lose the membrane area more rapidly than normal because their membranes are leaky and unstable. This incubation accentuates the defect in HS erythrocytes and brings out the defect on osmotic fragility, which is the the test routinely available for diagnosing HS. When spleen is present, a subpopulation of very fragile erythrocytes that have been conditioned by the spleen, form the tail of the osmotic fragility curve. This tail disappears after splenectomy.

\section{Acidified glycerol lysis test and Pink test}

The glycerol lysis test, in which glycerol is employed to retard the osmotic swelling of red cells, was developed as an alternative to the osmotic fragility test. It is based on the rate rather than on the extend of hemolysis. An acidified version, the acidified glycerol lysis test (AGLT) is more accurate if the samples are preincubated at room temperature for $24 \mathrm{~h}$. The half time for AGLT lysis is more than $30 \mathrm{~min}$ for normal samples, and less than $5 \mathrm{~min}$ for HS samples. Another adaptation for glycerol test called the Pink test is more reproducible but requires 1 day preincubation. ${ }^{24}$

\section{Hypertonic cryohemolysis test}

It is based on the fact that HS red cells are particularly sensitive to cooling at $0^{\circ} \mathrm{C}$ in hypertonic solutions. The test is independent of the surface/volume ratio which is an advantage compared to other tests. ${ }^{25}$

\section{Autohemolysis test}

The autohemolysis of erythrocytes after $48 \mathrm{~h}$ at $37^{\circ} \mathrm{C}$ is normal. In HS autohemolysis of spherocytes is increased by $15-45 \%$ in the absence of glucose, and reduces by the addition of glucose whereas in acquired disorders such as immune-mediated anemia, the degree of autohemolysis is not reduced. ${ }^{26}$

\section{Membrane protein analysis}

These useful tests include structural and functional studies of erythrocyte membrane protein such as protein quantitation, limited tryptic digestion of spectrin, membrane protein synthesis and assembly or ion transport studies. ${ }^{27,28}$

\section{Determination of the molecular defect}

Various mutation detection screening techniques have been employed, the most popular among them is the single stranded conformation polymorphism analysis. Mutation detection can be performed using direct nucleotide sequence analysis of polymerase chain reaction amplified genomic DNA or c DNA.

\section{Ektacytometry}

The deformability of erythrocytes (RBC) is measured in an ektacytometer, ${ }^{29}$ a laser-diffraction viscometer, as a continuous function of suspending medium osmolality. The ability of the RBC (diameter 6-8 $\mu \mathrm{m}$ ) to pass through the microvasculature (open- 
ings of 2-3 $\mu \mathrm{m}$ ) and splenic sinuses (openings of 0.5$1.0 \mu \mathrm{m})$ is referred to as deformability.

The resultant osmotic deformability profiles provide information on the viability of $\mathrm{RBC}$, cellular water content, surface area, deformability of the cell, heterogeneity within these cellular properties, and several pathological conditions, which are characterized by typical shifts in this curve.

\section{Treatment}

\section{Splenectomy}

Splenectomy ${ }^{30-32}$ is very effective in reducing hemolysis, leading to a significant prolongation of the red cell life span. The clinical manifestations and complications (anemia and gallstones) are much reduced in severe HS and abolished in milder cases but at the price of an increased risk of life-threatening sepsis from encapsulated organisms, particularly Streptococcus pneumonia. Recent evidence demonstrates that splenectomy for hereditary spherocytosis in children is very safe in the short term with no deaths and infrequent complications (less than $1 \%$ in 1657 splenectomies).

\section{Folic acid supplementation}

Folic acid ${ }^{33} 1 \mathrm{mg}$ daily and consideration for blood transfusions are recommended during periods of severe anemia.

\section{Hereditary elliptocytosis}

Hereditary elliptocytosis (HE) $)^{34}$ was first reported in 1904 by Dresbach, a physiologist at Ohio State University in Columbus who discovered the condition in one of his students during examining his own blood. Unfortunately the student died soon, and a number of famous pathologist's supported the view that elliptocytosis was a primary disorder and not a single morphologic finding differentiating from sickle cell anemia.

Hereditary elliptocytosis is an autosomal dominant disorder, characterized by the presence of elliptically shaped red cells on peripheral blood smear, more common in malaria endemic regions in West Africa (prevalence 2\%). 35,36

Similar to HS, the study of erythrocyte membrane proteins in these disorders has identified qualitative and/or quantitative abnormalities of various erythrocyte membrane proteins. These include ${ }^{36,37} \alpha$ and $\beta$ spectrin, protein 4.1 and glycophorin $C$. The majority of defects occur in spectrin, the principal structural protein of the erythrocyte membrane skeleton. Spectrin is composed of heterodimers of the related but non identical proteins $\alpha$ and $\beta$ spectrin that self-associate into tetramers and higher-order oligomers. Spectrin in- tegrity is critical for erythrocyte membrane stability and erythrocyte shape and function.

Structural $^{38}$ and functional defects of protein 4.1 appear to disrupt spectrin-actin contacts in the membrane skeleton. Glycophorin variants are also deficient in protein 4.1. The pathogenesis of the formation of elliptocytes in these syndromes is unknown.

\section{Clinical classification and manifestations}

Most of the reported cases of $\mathrm{HE}^{39,40}$ are classified into one of three categories: common, spherocytic elliptocytosis and Southeast Asian ovalocytosis (SAO).

The clinical features may appear with very severe transfusion-depended anemia (Hb: 2-6 g/dL), and severe hemolysis accompanied by evidence of membrane instability on the peripheral blood smear: budding red cells, fragments, and poikilocytes. Sometimes they develop uncompensated hemolysis in response to stimuli that cause hyperplasia of the reticuloendothelial system especially if the spleen is involved. In a small number of cases with typical partially dysplastic and ineffective HE erythropoiesis has been developed. The bone marrow is hyperplastic, with decreased late erythroblasts and dysplastic features such as asynchronous nuclear cytoplasmic maturation, binuclearity, and internuclear bridges. Unfortunately dysplasia persists after splenectomy.

Spherocytic elliptocytosis ${ }^{41}$ has been reported only in White European families. Spherocytic elliptocytes are osmotically fragile after incubation. Gallbladder disease is common. Splenic sequestration is evident and hemolysis abates after splenectomy.

Southern Asian ovalocytosis ${ }^{42}$ or Melanesian elliptocytosis ${ }^{43}$ is inherited in an autosomal dominant pattern. This results from the nine-amino-acid deletion of residues 400-408 due to $27 \mathrm{bp}$ deletion of the band 3 (AE1 or SLC4A1, anion-exchanger 1 gene).

The abnormality is very common in Melanesia where malaria is endemic. In vivo there is evidence that SAO provides some protection against heavy infections of cerebral malaria. In vitro SAO red cells are resistant to malarial parasites because the membrane is 10 to 20 times more rigid than normal.

\section{Hereditary pyropoikilocytosis}

Hereditary pyropoikilocytosis (HPP) ${ }^{44}$ is a rare cause of severe hemolytic anemia characterized by erythrocyte morphology reminiscent of that seen in patients after a thermal burn. It appears in early childhood as a severe hemolytic anemia characterized by extreme poikilocytosis. Patients typically present splenomegaly, hypebilirubinemia, growth retardation.

$\alpha$-spectrin mutations associated with HE and HPP 
are structural variants located in the heterodimer selfassociation region, the $\alpha$ I domain. In some cases, HPP is associated with homozygosity or compound heterozygosity for structural defects of the $\alpha$ I domain of spectrin. In other cases, there is compound heterozygosity for an $\alpha$ I domain structural variant and a production-defective $\alpha$-spectrin allele in trans associated with markedly decreased or absent normal $\alpha$ spectrin on the membrane. The parent who transmits the production-defective spectrin allele is clinically normal with unremarkable erythrocyte morphology because $\alpha$ spectrin is normally synthesized in a 2 - to 3 -fold excess and output from a single normal $\alpha$-spectrin allele is sufficient to maintain membrane integrity.

\section{Hereditary xerocytosis (high phosphatidylcholine hemolytic anemia)}

Hereditary xerocytosis (HX) or high phosphatidylcholine hemolytic anemia ${ }^{45,46}$ is a rare disease among the types of hemolytic anemia. A dominantly transmitted chronic anemia characterized by an increase in erythrocyte membrane phosphatidylcholine and cholesterol with decrease in phosphatidylethanolamine. Stomatocytes and target cells are evident on peripheral blood smears.

Xerocytosis is characterized by a reduction in the cell potassium content, the main intracellular cation. This may be associated with a slight increase in cell sodium content, but the total cation content of the red cell is significantly lower than in normal controls.

The dehydrated cells are more resistant to lysis when incubated in hypotonic solutions. This decrease in osmotic fragility is due to the small baseline cell size. On the other hand, xerocytes exhibit a characteristic increase in cell rigidity and reduction in cell deformability. These changes are thought to play an important role in the hemolysis resulting from premature destruction of xerocytes. A genome-wide search for patients with hereditary xerocytosis has mapped this disorder to a locus on chromosome 16q24.2-16qter. ${ }^{47}$ Familial pseudohyperkalemia, a disorder in which red cells show a temperature-dependent leakage of potassium in collected blood, maps to the same locus. It has been suggested that about one-third of hereditary xerocytosis kindred demonstrate pseudohyperkalemia. ${ }^{48}$

Hereditary xerocytes appear to be macrocytic despite their dehydration. Splenectomy is probably not beneficial in HX.

\section{Mediterranean stomatocytosis}

Mediterranean stomatocytosis ${ }^{49,50}$ or Mediterranean macrothrombocytopenia is a poorly understood hematological condition that combines stomatocytic hemolysis with the presence of very large platelets. Gas chromatography mass spectrometry showed that all patients with this highly specific hematology had grossly elevated levels of phytosterols in the blood, diagnostic of phytosterolemia. This syndromic association between stomatocytic hemolysis and macrothrombocytopenia and slight splenomegaly was first identified among Australian residents of Mediterranean extraction.

\section{Acanthocytosis with neurologic disease (amyotrophic chorea-acanthocytosis)}

Amyotrophic choreo-acanthocytosis ${ }^{51,52}$ is a rare disease of adult onset characterized by dyskinesias, neurogenic muscular atrophy, erythrocytary acanthocytosis with normal serum lipoproteins and elevated levels of serum creatine phosphokinase. This disease has been described among Japanese, English, Finnish and Puerto Rican people. No formal diagnostic criteria for chorea-acanthocytosis exist. The diagnosis is based on recognizing the characteristic clinical features with peripheral acanthocytosis and normal lipid studies. Particularly in male patients, testing for the McLeod blood phenotype should be considered because McLeod syndrome may present indistinguishably from chorea-acanthocytosis.

Because of the gene expression in RBCs, the western blot of a patient's erythrocyte membranes with antichorea antisera may become a useful initial diagnostic test. ${ }^{53}$

Follow-up mutational analysis of the VPS13A gene $^{54}$ can be performed, however, this is challenging due to the large size of the gene and the heterogeneity of mutation sites. Molecular genetic testing for VPS13A mutations is not widely available.

Clinically, this disorder is characterized by the onset in young adulthood of chorea and/or Parkinsonism, oro-lingual-facial dystonias, tics, social disinhibition, seizures, areflexia, and distal muscle wasting. The mean age of onset is 35 years with a broad range from the first to the seventh decade. Initial clinical symptoms can vary. No curative or disease modifying treatment for chorea-acanthocytosis currently exists. Treatment is aimed at symptom management. A multidisciplinary approach to disease management is recommended.

\section{References}

1. Smith Payne A. The cleere observer: a biography of Antoni van Leeuwenhoek. London: Macmillan; 1970.

2. Mohandas N, Gallagher PG. Red cell membrane: past, present, and future. Blood 2008;112:3939-48.

3. Perrotta S, Gallagher PG, Mohandas N. Hereditary spherocytosis. Lancet 2008;372:1411-26. 
4. Iolason A, Avvisati RA, Piscopo C. Hereditary spherocytosis. Transfusion Clin Biol 2010;17:138-42.

5. Salomao M, Chen K, Villalobos J, et al. Hereditary spherocytosis and hereditary elliptocytosis: aberrant protein sorting during erythroblast enucleation. Blood 2010; 116:267-9.

6. Agre P, Orringer EP, Bennett V. Deficient red-cell spectrin in severe, recessively inherited spherocytosis. N Engl J Med 1982;306:1155-61.

7. Eber S, Lux SE. Hereditary spherocytosis - defects in proteins that connect the membrane skeleton to the lipid bilayer. Semin Hematol 2004;41:118-41.

8. Seldin MF, Morse HC 3rd, Reeves JP, et al. Genetic analysis of autoimmune gld mice. I. Identification of a restriction fragment length polymorphism closely linked to the gld mutation within a conserved linkage group. J Exp Med 1988;167:688-93.

9. Lanciotti M, Perutelli P, Valetto A, et al. Ankyrin deficiency is the most common defect in dominant and non dominant hereditary spherocytosis. Haematologica 1997; 82:460-2

10. Eber S, Lux SE. Hereditary spherocytosis - defects in proteins that connect the membrane skeleton to the lipid bilayer. Semin Hematol 2004;41:118-41.

11. Gallagher PG, Sabatino DE, Basseres DS, et al. Erythrocyte ankyrin promoter mutations associated with recessive hereditary spherocytosis cause significant abnormalities in ankyrin expression. J Biol Chem 2001; 276:41683-9.

12. Bruce LJ, Beckmann R, Ribeiro ML, et al. A band 3based macrocomplex of integral and peripheral proteins in the RBC membrane. Blood 2003;101:4180-8.

13. Zhang D, Kiyatkin A, Bolin JT, Low PS. Crystallographic structure and functional interpretation of the cytoplasmic domain of erythrocyte membrane band 3 . Blood 2000;96:2925-33.

14. White RA, Peters LL, Adkison LR, et al. The murine pallid mutation is a platelet storage pool disease associated with the protein 4.2 (pallidin) gene. Nature Genet 1992;2:80-3.

15. Yawata Y, Kanzaki A, Yawata A. Genotypic and phenotypic expressions of protein 4.2 in human erythroid cells. Gene Funct Dis 2000;1:61-81.

16. Zwaal RF, Schroit AJ. Pathophysiologic implications of membrane phospholipid asymmetry in blood cells. Blood 1997;89:1121-32.

17. Gallagher PG. Red cell membrane disorders. ASH Education Program Book 2005;2005:13-8.

18. Mariani M, Barcellini W, Vercellati C, et al. Clinical and hematologic features of 300 patients affected by hereditary spherocytosis grouped according to the type of the membrane protein defect. Haematologica 2008; 93:1310-7.

19. Bolton-Maggs PH, Stevens RF, Dodd NJ, et al. Guidelines for the diagnosis and management of hereditary spherocytosis. Br J Haematol 2004;126:455-74.

20. Vermeulen S, Messiaen L, Scheir P, et al. Kallmann syndrome in a patient with congenital spherocytosis and an interstitial 8p11. 2 deletion. Am J Med Genet 2000;108: 315-8.

21. Saç R, Güveloglu M, Bostanc1 I, et al. The association of immune thrombocytopenic purpura with hereditary spherocytosis. Marmara Med J 2009;22:142-5.
22. Cynober T, Mohandas N, Tchernia G. Red cell abnormalities in hereditary spherocytosis: relevance to diagnosis and understanding of the variable expression of clinical severity. J Lab Clin Med 1996;128:259-69.

23. Bianchi P, Fermo E, Vercellati C, et al. Diagnostic power of laboratory tests for hereditary spherocytosis: a comparison study in 150 patients grouped according to molecular and clinical characteristics. Haematologica 2012;97:516-23.

24. Bucx MJL, Breed WPM, Hoffmann JJML. Comparison of acidified glycerol lysis test, Pink test and osmotic fragility test in hereditary spherocytosis: effect of incubation. Eur J Haematol 1998;40:227-31.

25. Streichman S, Gescheidt Y. Cryohemolysis for the detection of hereditary spherocytosis: correlation studies with osmotic fragility and autohemolysis. Am J Hematol 1998;58:206-12.

26. Crisp RL, Solari L, Vota D, et al. A prospective study to assess the predictive value for hereditary spherocytosis using five laboratory tests (cryohemolysis test, eosin-5'maleimide flow cytometry, osmotic fragility test, autohemolysis test, and SDS-PAGE) on 50 hereditary spherocytosis families in Argentina. Ann Hematol 2011; 90:625-34.

27. King MJ, Behrens J, Rogers C, et al. Rapid flow cytometric test for the diagnosis of membrane cytoskeletonassociated haemolytic anaemia. Br J Haematol 2000; 111:924-33.

28. Delhommeau F, Cynober T, Schischmanoff PO, et al. Natural history of hereditary spherocytosis during the first year of life. Blood 2000;95:393-7.

29. Huisman A, van Wijk R. Ektacytometry and genetic testing in hereditary red cell membrane disorders. Int J Lab Hematol 2014;36:107.

30. Bader-Meunier B, Gauthier F, Archambaud F, et al. Long-term evaluation of the beneficial effect of subtotal splenectomy for management of hereditary spherocytosis. Blood 2001;97:399-403.

31. Schilling RF, Gangnon RE, Traver MI. Delayed adverse vascular events after splenectomy in hereditary spherocytosis. J Thromb Haemost 2008;6:1289-95.

32. Stoehr GA, Sobh JN, Luecken J, et al. Near-total splenectomy for hereditary spherocytosis: clinical prospects in relation to disease severity. $\mathrm{Br} \mathrm{J}$ Haematol 2006;132:791-3.

33. Murray NA, Roberts IAG. Haemolytic disease of the newborn. Archiv Dis Child 2007;92:F83-8.

34. Palek J. Hereditary elliptocytosis and related disorders. Clin Haematol 1985; 14:45.

35. Dash S. Hemoglobinopathies, G6PD deficiency, and hereditary elliptocytosis in Bahrain. Hum Biol 2004;76: 779-83.

36. Dhermy D, Schrével J, Lecomte M-C. Spectrin-based skeleton in red blood cells and malaria. Curr Opin Hematol 2007;14:198-202.

37. Alloisio N, Morlé L, Pothier B, et al. Spectrin Oran (alpha II/21), a new spectrin variant concerning the alpha II domain and causing severe elliptocytosis in the homozygous state. Blood 1988;71:1039-47.

38. Coetzer T, Palek J, Lawler J, et al. Structural and functional heterogeneity of alpha spectrin mutations involving the spectrin heterodimer self-association site: relationships to hematologic expression of homozygous 
hereditary elliptocytosis and hereditary pyropoikilocytosis. Blood 1990;75:2235-44.

39. Roberts HR, Hoffman M. Hemophilia A and hemophilia B. In: Beutler E, Lichtman MA, Coller BS, et al., eds. Williams hematology. New York, NY: McGraw-Hill; 2001. pp 1650-1655.

40. Gallagher PG, Bernard G. Hereditary spherocytosis, elliptocytosis and related disorders. In: Beutler E, Lichtman MA, Coller BS, et al., eds. Williams hematology. New York, NY: McGraw-Hill; 2001. pp 503-518.

41. Delaunay J. The hereditary stomatocytoses: genetic disorders of the red cell membrane permeability to monovalent cations. Semin Hematol 2004;41:165-72.

42. Wrong O, Bruce LJ, Unwin RJ, et al. Band 3 mutations, distal renal tubular acidosis, and Southeast Asian ovalocytosis. Kidney Int 2002;62:10-9.

43. Facer CA. Malaria, hereditary elliptocytosis, and pyropoikilocytosis. Lancet 1989;1:897.

44. Peterson LC, Dampier C, Coetzer T, et al. Clinical and laboratory study of two Caucasian families with hereditary pyropoikilocytosis and hereditary elliptocytosis. Am J Clin Pathol 1987;88:58-65.

45. Vives Corrons JL, Besson I, Aymerich M, et al. Hereditary xerocytosis: a report of six unrelated Spanish families with leaky red cell syndrome and increased heat stability of the erythrocyte membrane. Br J Haematol 1995;90:817-22.

46. Stewart GW, Turner EJH. The hereditary stomatocytoses and allied disorders: congenital disorders of erythrocyte membrane permeability to $\mathrm{Na}$ and K. Best Pract Res Clin Haematol 1999;12:707-27.

47. Zarychanski R, Schulz VP, Houston BL, et al. Mutations in the mechanotransduction protein PIEZO1 are associated with hereditary xerocytosis. Blood 2012;120:1908-15.

48. Coles SE, Ho MM, Chetty MC, et al. A variant of hereditary stomatocytosis with marked pseudohyperkalaemia. Br J Haematol 1999;104:275-83.

49. Bruce LJ. Hereditary stomatocytosis and cation leaky red cells - recent developments. Blood Cells Mol Dis 2009;42:216-22.

50. Rees DC, Iolascon A, Carella M, et al. Stomatocytic haemolysis and macrothrombocytopenia (Mediterranean stomatocytosis/macrothrombocytopenia) is the haematological presentation of phytosterolaemia. $\mathrm{Br} \mathrm{J}$ Haematol 2005;130:297-309.

51. Stevenson VL, Hardie RJ. Acanthocytosis and neurological disorders. J Neurol 2001;248:87-94.

52. Wong P. A basis of the acanthocytosis in inherited and acquired disorders. Med Hypotheses 2004;62:966.

53. Cardoso F, Seppi K, Mair KJ, et al. Seminar on choreas. Lancet Neurol 2006;5:589-602.

54. Bader B, Velayos-Baeza A, Walker RH, Danek A. Dominant transmission of chorea-acanthocytosis with VPS13A mutations remains speculative. Acta Neuropathol 2009;117:95-6. 